\title{
Optimizing endotracheal tube size and length for tracheal intubation through single-use supraglottic airway devices
}

\author{
Ichiro Takenaka, MD • Kazuyoshi Aoyama, MD
}

Received: 4 December 2009/ Accepted: 14 January 2010/Published online: 27 January 2010

(C) Canadian Anesthesiologists' Society 2010

\section{To the Editor,}

Supraglottic airway devices have an established role in facilitating tracheal intubation in the setting of difficult airway management. ${ }^{1}$ When the laryngeal mask airway (LMA) Classic ${ }^{\mathrm{TM}}$ (LMA North America Inc., San Diego, CA, USA) ${ }^{\mathrm{A}}$ is used as an airway conduit for tracheal intubation, there are several limitations regarding the compatibility of endotracheal tubes (ETT), because the ETTs must be passed through the relatively narrow and long airway tube of the LMA. ${ }^{1,2}$ Recently, single-use supraglottic airway devices that have configurations similar to that of the LMA Classic have been introduced. These single-use devices include the LMA Unique ${ }^{\mathrm{TM}}$ (LMA North America Inc., San Diego, CA, USA), ${ }^{\mathrm{A}}$ the Soft Seal Laryngeal Mask ${ }^{\mathrm{TM}}$ (Smiths Medical Ltd., Hythe, Kent, $\mathrm{UK}$ ), ${ }^{\mathrm{B}}$ the AuraStraight ${ }^{\mathrm{TM}}$ (Ambu Inc., Glen Burnie, MD, USA), ${ }^{\mathrm{C}}$ and the AuraOnce ${ }^{\mathrm{TM}}$ (Ambu Inc., Glen Burnie, MD, USA). ${ }^{\mathrm{D}}$ The effectiveness of these devices to facilitate tracheal intubation has been investigated. ${ }^{3}$ Compared with the LMA Classic, these airways differ slightly in their structure. For instance, each of these new single-use supraglottic airways has a unique internal diameter and length, hence, options regarding both the size and length of ETTs that can be used for tracheal intubation may differ from that of the LMA Classic. These differences may be especially important when using these devices in emergent settings. ${ }^{1}$ We undertook a comparison of the diameters and lengths of ETTs that can be used for tracheal intubation through each of these supraglottic airways.

I. Takenaka, MD $(\bowtie) \cdot$ K. Aoyama, MD

Nippon Steel Yawata Memorial Hospital, Yahatahigashi-ku, Kitakyushu, Japan

e-mail: takenaka.i@ns.yawata-mhp.or.jp
This comparison revealed that the minimum length of ETT that could be considered suitable to advance through the supraglottic airway was deemed to be the sum of the length of the airway tube of the supraglottic airway, the distance between the mask aperture and the vocal cords (ranging from 2.0 to $4.7 \mathrm{~cm}$ ), ${ }^{2}$ and the distance between the upper border of the ETT cuff and the ETT tip, i.e., $\leq 5.5 \mathrm{~cm}$ in a 6 or $6.5 \mathrm{~mm}$ ETT and $\leq 6.5 \mathrm{~cm}$ in a $7 \mathrm{~mm}$ ETT (Table 1). Thus, when the ETTs are passed through the supraglottic airway to the maximum extent possible, $6 \mathrm{~mm}$ and $7 \mathrm{~mm}$ internal diameter ETTs are required to project about $10 \mathrm{~cm}(4.7+5.5 \mathrm{~cm})$ and $11 \mathrm{~cm}$ $(4.7+6.5 \mathrm{~cm})$, respectively, beyond the mask aperture.

The airway tube of the LMA Unique is equal in both internal diameter and length to that of the LMA Classic, which needs a longer ETT (Tables 1 and 2). While the length of the Soft Seal Laryngeal Mask is similar to that of the LMA Classic, the former tube is thicker (Table 2). Thus, when using the Soft Seal Laryngeal Mask for tracheal intubation, a longer ETT is needed (Table 1); however, in comparison with the LMA Classic, a large bore ETT can be used (Table 2). In contrast, the airway tube of the AuraStraight has the same internal diameter as that of the LMA Classic, but the tube length is shorter (Table 2). Thus, when using the AuraStraight, normal length ETTs can be used in most cases for tracheal intubation.

\footnotetext{
A LMA North America Inc. LMA ${ }^{\mathrm{TM}}$ airway instruction manual. San Diego, CA, USA: LMA North America Inc.; 2005.

B Smiths Medical Ltd. Portex Soft Seal Laryngeal Mask ${ }^{\mathrm{TM}}$ instruction for use. Hythe, Kent, UK: Smiths Medical Ltd.; 2006.

${ }^{\mathrm{C}}$ Ambu Inc. AuraStraight ${ }^{\mathrm{TM}}$ product information. Glen Burnie, MD, USA: Ambu Inc.; 2007.

D Ambu Inc. AuraOnce ${ }^{\mathrm{TM}}$ product information. Glen Burnie, MD, USA: Ambu Inc.; 2008.
} 
Table 1 Endotracheal tube (ETT) sizing for tracheal intubation through single use supraglottic airways

\begin{tabular}{lllll}
\hline & ID $(\mathrm{mm})$ & OD $(\mathrm{mm})$ & Total length $(\mathrm{cm})$ & $\begin{array}{l}\text { Distance between the } \\
\text { cuff and the tip* }\end{array}$ \\
\hline MLT $^{\mathrm{TM}}$ (Mallinckrodt Medical) & 6 & 8.2 & 33 & 5 \\
RAE $^{\mathrm{TM}}$ Nasal (Mallinckrodt Medical) & 6 & 8.2 & 35 & 5 \\
Northpolar & & 5 \\
RAE $^{\mathrm{TM}}$ Nasal (Mmiths Medical)** & 6 & 8.8 & 40 & 5 \\
\hline
\end{tabular}

$\mathrm{ID}=$ interneal diameter; OD $=$ outer diameter

* Distance between the upper border of the ETT cuff and the ETT tip is measured

** Be aware of possible rupture of the ETT cuff when passing through a 15-mm airway connector due to a larger OD

Table 2 Endotracheal tube (ETT) for tracheal intubation through single use supraglottic airways

\begin{tabular}{|c|c|c|c|c|c|c|c|c|c|c|c|c|c|c|c|}
\hline \multirow[b]{2}{*}{ Supraglottic airway size } & \multicolumn{3}{|c|}{ LMA Classic $^{\mathrm{TM}}$} & \multicolumn{3}{|c|}{ LMA Unique $^{\mathrm{TM}}$} & \multicolumn{3}{|c|}{$\begin{array}{l}\text { Soft Seal } \\
\text { Laryngeal Mask }^{\mathrm{TM}}\end{array}$} & \multicolumn{3}{|c|}{ AuraStraight $^{\mathrm{TM}}$} & \multicolumn{3}{|c|}{ AuraOnce $^{\mathrm{TM}}$} \\
\hline & 3 & 4 & 5 & 3 & 4 & 5 & 3 & 4 & 5 & 3 & 4 & 5 & 3 & 4 & 5 \\
\hline Maximum internal diameter of the ETT $(\mathrm{mm})$ & 6 & 6 & 7 & 6 & 6 & 7 & 6.5 & 7 & 7.5 & 6 & 6 & 7 & 5.5 & 6 & 7 \\
\hline $\begin{array}{l}\text { Length of the airway tube of the } \\
\text { supraglottic airway* }(\mathrm{cm})\end{array}$ & 20 & 20 & 22 & 20 & 20 & 22 & 19 & 20 & 22 & 18 & 18 & 20 & 17 & 19 & 22 \\
\hline Minimum length of the ETT** $(\mathrm{cm})$ & 30 & 30 & 33 & 30 & 30 & 33 & 29 & 30 & 33 & 28 & 28 & 31 & 27 & 29 & 33 \\
\hline
\end{tabular}

LMA = laryngeal mask airway

* Distance between the upper end of the $15 \mathrm{~mm}$ connector and the mask aperture. These measures may differ from data in the corresponding instruction manuals.

** Minimum ETT length is calculated as the sum of length of the airway tube and $10 \mathrm{~cm}$ (5.5 or $6.5 \mathrm{~mm}$ ETT) or $11 \mathrm{~cm}$ (7 mm ETT). The latter is the sum of distance between the mask aperture and the vocal cords, and the distance between the upper border of the ETT cuff and the ETT tip

In conclusion, we examined optimal ETT size and length for tracheal intubation through single-use supraglottic airways. Since errors of $\pm 5 \mathrm{~mm}$ in the length of both the ETT and the airway tube of the airways are considered, we strongly recommend that longer ETTs be available at all times. To avoid rupturing the ETT cuff, it is also important to advance the ETT gently into the narrowest part of the system, which is the $15 \mathrm{~mm}$ connector. ${ }^{4}$

Acknowledgements This work is attributable to the Department of Anesthesia, Nippon Steel Yawata Memorial Hospital, Kitakyushu, Japan. Financial support was provided solely from institutional and/or departmental sources. The authors have no affiliation with any manufacturer of any medical devices described in the manuscript.

\section{References}

1. Crosby ET, Cooper RM, Douglas MJ, et al. The unanticipated difficult airway with recommendations for management. Can J Anaesth 1998; 45: 757-76.

2. Asai T, Latto IP, Vaughan RS. The distance between the grille of the laryngeal mask airway and the vocal cords. Is conventional intubation through the laryngeal mask safe? Anaesthesia 1993; 48: 667-9.

3. Danha RF, Thompson JL, Popat MT, Pandit JJ. Comparison of fibreoptic-guided orotracheal intubation through classic and singleuse laryngeal mask airways. Anaesthesia 2005; 60: 184-8.

4. Wong DT, McGuire GP. Endotracheal intubation through a laryngeal mask/supraglottic airway. Can J Anesth 2007; 54: 489-91.

Conflicts of interest None declared. 